\title{
Cloud Opera through the prism of artistic research: looking for media archaeological issues from the clouds
}

$\$$ sciendo 


\section{ABSTRACT}

Cloud Opera or The Dido Problem (Vaba Lava, Tallinn, Feb-Mar 2019) is a theatrical performance investigating, through artistic means, the human condition in the datafied world. The play was created in collaboration between Vaba Lava theatre and Tallinn University's Centre of Excellence in Media Innovation and Digital Culture (MEDIT). In terms of its representations, the play combined references to man-made data 'clouds' with knowledge on atmospheric clouds and suggested that the former are just as unpredictable and uncontrollable as the latter. In this article, Liina Keevallik, the author and the scenographer of the performance together with Indrek Ibrus, a media researcher, discuss the uses of the media archaeological approach both in artistic practice and in creating "Cloud Opera". We also discuss what media archaeological "findings" we could glean from the scenic elements of the play.

\section{WHY CLOUDS?}

Why carry out interdisciplinary and intermodal (artistic, analytic, scientific) exploration of such a vague and abstract, as well as rhetorically and discursively loaded matter as clouds? The first and the simplest answer is: because we have problems with clouds. To be more precise: with both kinds of clouds - the atmospheric ones as well as the metaphorical ones, the data carriers. Both kinds of clouds are saturated with threatening substances. The first kind sometimes with unhealthy smoke and the second with an overdose of data traced, often in covert ways, in much of the social world. The clouds are full of secrecies and violations.

Another reason talking about 'clouds' has become timely is their potential ability to blur the picture. The images on all possible screens around us are increasingly sharper, there are more pixels on our screens than in real life. Screens tend to augment our lives, take them to the domain of the hyperreal (Eco 1986). Clouds (and fog) could help to balance the situation. This question is not only an aesthetical issue, as 'clouding' may be needed for dealing with the overload of information. Digital umwelt (von Uexküll 1957) consists of very 'sharp' bits, that become, perhaps paradoxically, fuzzy in vast quantities. New poetic forms of sense-making may be needed to establish appropriate balances between the sharpness and fuzziness of our umwelts. (Figure 1)

It is for these two reasons, one representing challenges (data clouds and the condition of the atmosphere in the Anthropocene), the other opportunities (the necessity to cloud the cognitive overload), that this article addresses 'clouds' as connotatively charged signifiers. Our study was carried out from the viewpoint of artistic 
research, but informed by the media archaeological method. We analysed the Cloud Opera, a performance rhetorically merging the references to both atmospheric and data clouds. After a short overview of the Cloud Opera project, we will look at the possible media archaeological means that could be activated while talking about clouds. In the following, we will discuss some very particular problems emerging from the Cloud Opera; we will observe the phenomenon of a cloud in the light of the emerging media-theoretical or historical issues. The question is: what can we learn when addressing how 'clouds' are used in media and arts using media archaeological tools? This article aims at observing the evaporative matter that clouds of various kinds are made of and finding elements of the theatrical performance - direct or metaphorical - that would let themselves be analysed by media theory. (Figure 2)

\section{THE CLOUD OPERA}

Cloud Opera or The Dido Problem is a performance that addresses the human condition under a 'sky full of data'. It combines references to man-made data 'clouds' with real atmospheric clouds and suggests that the first are just as unpredictable and uncontrollable as the latter. The production is part of the 2018-2019 curatorial program of the Vaba Lava performing arts centre in Estonia, which focused on the phenomena of 'post-truth' and 'big data'. As these immense subjects consist of very diverse sets of questions and sub-topics, the genre of "opera" proved to be the apt form: it is generally perceived as a privileged art form allowed to play around with serious themes superficially, but very loudly.

This mass of information gathered in the 'clouds - is constantly above us, and can rain down in the most surprising or sometimes unpleasant ways. In fact, we are facing a cruel new truth - the gentle clouds, once the soft celestial cushions for our cherubs' bottoms, are now invaded by Big Data and its contagious profusion of information. Formerly, the 'clouds' referred to the realm of God and Chance, yet in con- temporary discourse they house a sort of giant bric-a-brac shop where one can go shopping or shoplifting, peek for mysteries, fish for valuables or perhaps just drown in the white noise. Chance, however, continues to reside in the clouds and play a key role in the course of events.

The performance set a contradiction between the intimate action of the vulnerable humans on the stage below, and the massive choir, often cacophonic, who represented Big Data and the chaos up in the clouds. Intervention from above can arrive at any moment, creating havoc for those below. There were 4 actors-singers on the lower realm and anywhere up to 40 choir singers in the clouds above (technically speaking: on the technical bridges above the stage).

The 4 actors play multiple roles. Here is a list of these roles alongside some historical and physical facts that inspired their existence:

1. The IT-genius - Know-it-all, King of the Data Clouds, a hacker (Figure 3)

The computer geek has a big project - to found a 'Cloud Embassy' - a strategy for conserving all the data of a country in a cloud 'above' another country. In order to do this it is necessary to rent 1 symbolic square meter in the host country. The embassy would be used in the case of a cyber-attack or invasion ${ }^{1}$. In the play, the IT-genius rules the data world, he has all the possible passwords, until the moment his own memory starts letting him down.

\section{The Nurse - The new-age esoteric} woman, the racist, the mother of the computer geek, the god-seeking figure looking for any signs in the universe and reading Schopenhauer to her patients. (Figure 4)

Her alter ego is a kitschy and conservative Virgin Mary (Figure 5), descending from the heavens and preaching to people, using the rhetoric of a typical post-truth politician. The Nurse slips more and more

\footnotetext{
This is a reference to Estonia's official policy and practice of storing copies of all its e-government data in servers housed in friendly countries.
} 

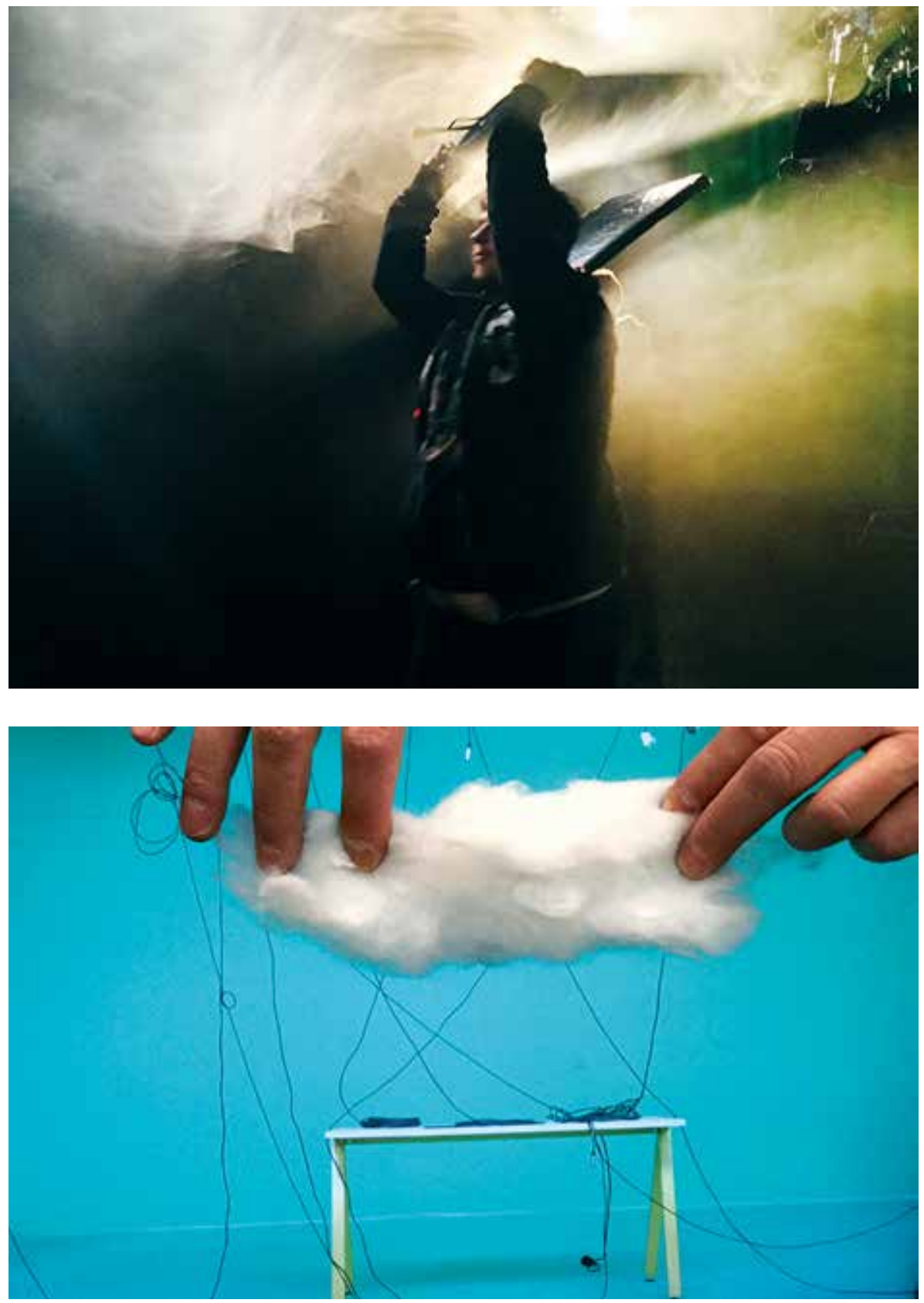

FIGURE 1. Preparing the shooting of the trailer for Cloud Opera (photo: Christina Batman).

FIGURE 2. Choosing the material for the clouds.

Preparing the shooting of the trailer for Cloud Opera (photo: Christina Batman). 

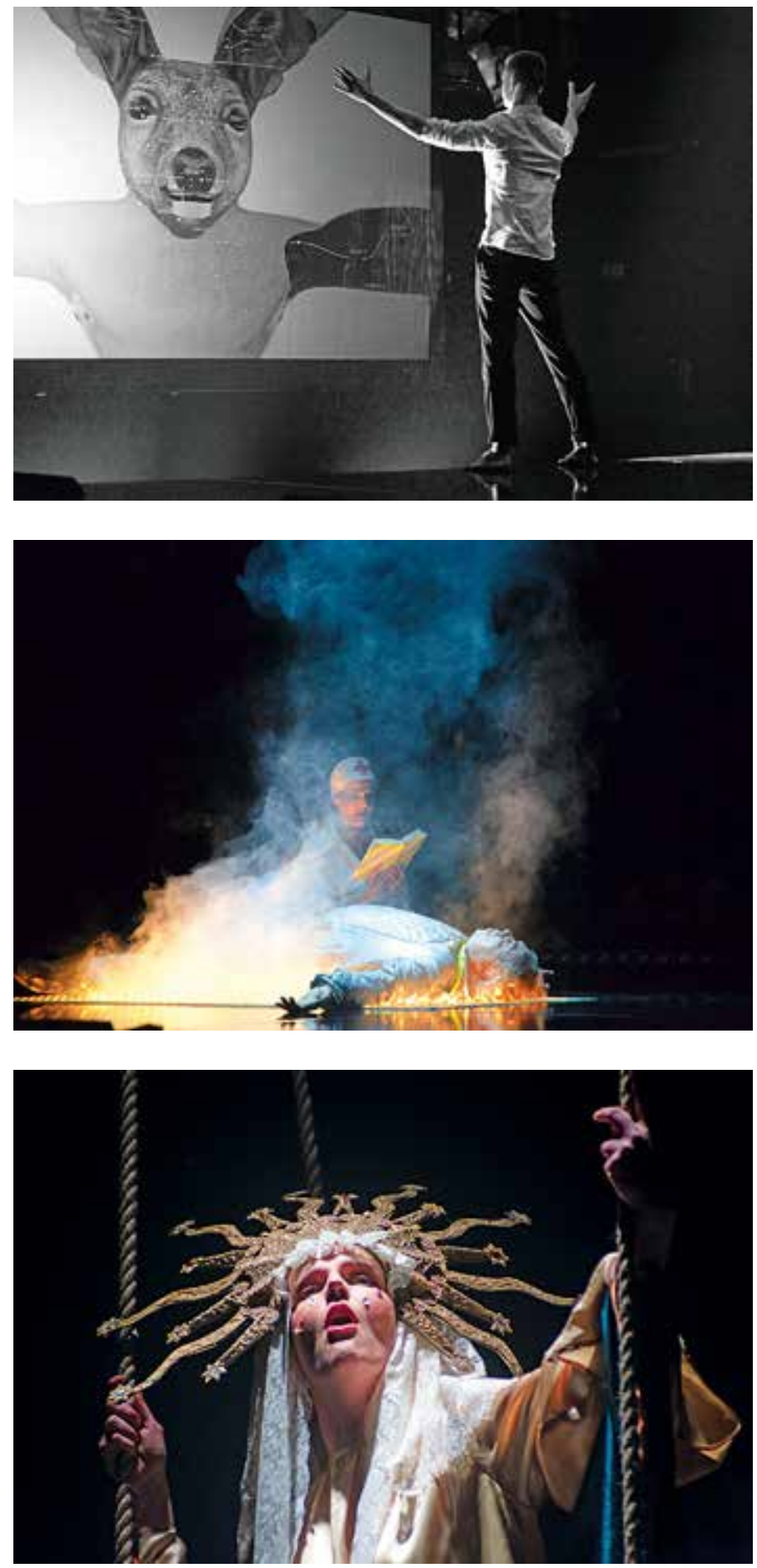

FIGURE 3. The IT-genius (Siim Tôniste) (photo: Markus Muide).

FIGURE 4. The Nurse (Liina Vahtrik) (photo: Liina Keevallik).

FIGURE 5. The Madonna (Liina Vahtrik) (photo: Markus Muide). 
into the realm of the esoteric, especially after having had an online affair with her own son.

3. Dido - The stranger, the mythical character, Queen and founder of Carthage whose story was "hacked" by Virgil ${ }^{2}$ and repossessed by so many artists. (Figure 6) Dido's story was modified to suit Virgil's need to tell the story of the glory of the founding of Rome. She became better known for Virgil's romantic melodrama and for her famous lovelorn suicide than anything else, thus providing excellent material for tearful operas and theatre pieces. The most famous of them is certainly Purcell's "Dido and Aeneas". What we know less of is the genial way she played a trick to gain more land for her people by asking the local king for a piece of land the size of an ox skin. She then cuts the ox skin into a fine thread, as a clever subterfuge, in order to obtain a sufficient amount of land to found Carthage, which strangely resembles the 'cloud embassy project for the e-state of Estonia. Compared to the "small, local community" represented on the stage by the Nurse, the IT-genius and the Scientist, Dido is a metaphor for the whole world, a scary stranger speaking in "bird language" and wearing the "satellite photo" dress, walking around with a plug in her hand and a loudspeaker instead of a suitcase. (Figure 7) When she finally gets some electricity, Google starts translating the bird sounds.

The 'Dido Problem' is known in mathematics as an isoperimetric enigma.

\section{The Scientist - He represents the real historical scientists and other figures that have researched clouds. (Figure 8) The Scientist is doing a Sisyphus' job, trying to get closer to the secrets of the sky. As clouds play ugly tricks on him - they cover Venus when the Scientist has been waiting for 8 years to see the planet pass in front of the Sun; they "pee" on his painting after he has decided to capture the clouds by getting them down to the canvas. In paral-}

2 The myth of Dido and Aeneas, Book IV of Virgil's Aeneid. lel, the data clouds bully him too by saying that the webpage he seeks no longer exists, etc. In the end, the Scientist is completely offended by the clouds and points his latest invention - the "cloudbuster" (Table 1) - at them to shoot them down.

Table 1 is an example of "blurring" the information by simply adding as many facts as possible so that the big picture goes out of focus. It can also be seen as a technique of poeticizing - mixing all the concrete features of historical figures in one character results in a multitude of information dissolving into a fuzzy abstraction. The same thing happens to the sudden avalanches of text in the play - every character has a monologue that stands out of the context with extreme talkativeness (the rest of the spoken text is extremely minimal). The sudden multitude of words has the same kind of impact, the information grows dizzy and the actors seem eventually to be speaking in a bird language, like Dido. As in real opera, the words are not necessarily understandable.

Poetry being blurrier than reality is a good old romanticist cliché: veils and clouds referring to the inner state of the romantic hero, streams of thick fog representing the unconscious feelings. The cliché of showing the mental condition of a character by the weather still lives in TV and mediocre cinema. This brings up two questions: firstly, the notion of too much information becoming blurry (as Roger Bacon already mentioned), in both the visual and the metaphorical field. According to the photography theorist Papadimitropoulos Panayotis:

The hyper complexity of the modern world leads to an impossibility of understanding what's going on, of stepping in and correcting what's wrong. Facing this reality check, we no longer know what kind of a behaviour we should adapt to. This hyper complexity is out of human control. Man can no longer decipher the relations between existing things, although 

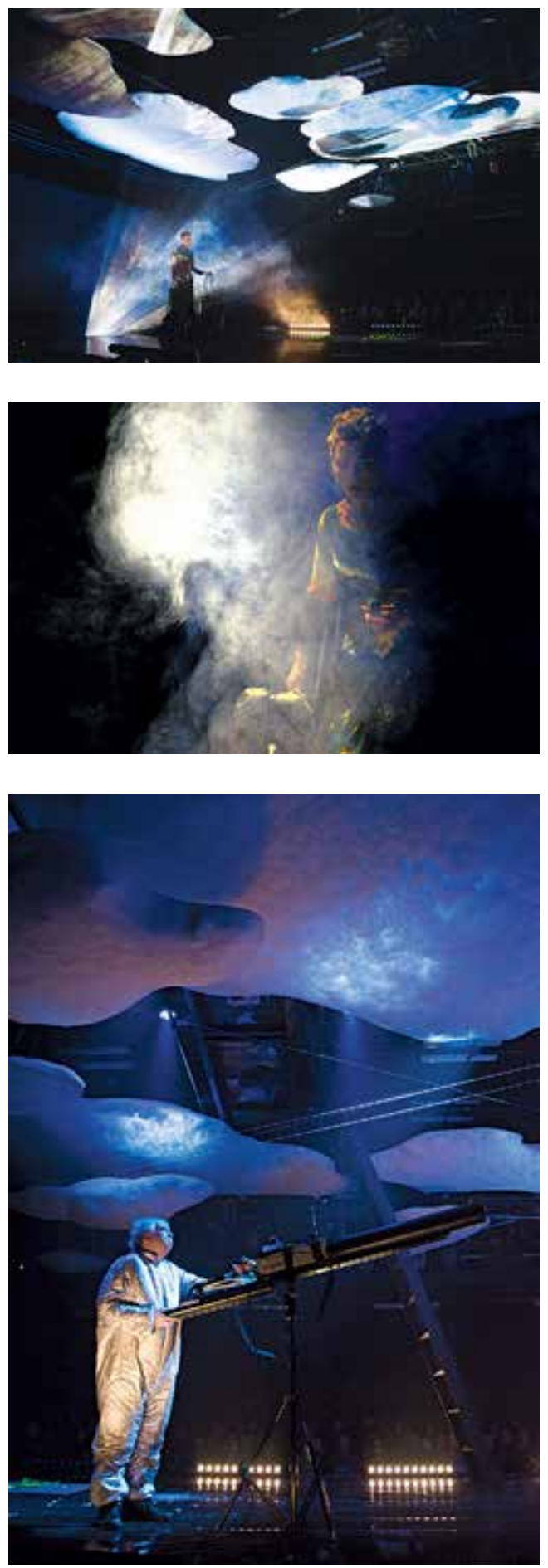

FIGURE 6. Dido (Christina Batman) (photo: Markus Muide).

FIGURE 7. Dido asking for a wall socket in bird language (photo: Liina Keevallik).

FIGURE 8. The Scientist (Lauri Saatpalu) (photo: Markus Muide). 
Luke Howard

John Constable

Wilhelm Reich

Guillaume le Gentil

Glaisher \& Coxwell

Albert Einstein

Hiroshima the reserved, amateur meteorologist that gave the clouds their first names in 1801 (Cirrus, Stratus, Cumulus etc.). Goethe admired him and was inspired to write poetry in his honour.

the great virtuoso painter of clouds who, according to legend, developed a technique for drawing clouds quickly at the perfect moment, after having observed them for inspiration for long hours.

a political theoretician and a disciple to Freud who invented the «cloudbuster», a machine that was used in 1953 to create rain in order to ease the drought taking place on a blueberry farm.

a French astronomer who was famous for his bad luck during his attempts to observe the passage of Venus in front of the sun. Having missed the event in 1761, he made preparations for 8 years to go to India in 1769. On the big day, the clouds filled the sky and obstructed his view.

James Glaisher and Henry Coxwell were the first scientists to attain the stratosphere in a hot air balloon in 1862. One of them had frozen extremities and the other nearly died from lack of oxygen. They both heard a celestial group playing music up in the clouds.

the theory of relativity would not have been discovered on that precise day in 1919 had there been the presence of clouds in the sky.

had the sky not been free of clouds above the city on the 6th of August 1945, the bombers would probably have chosen another town to bomb.

TABLE 1. List of historical figures used in creating the Scientist's character. 
he has turned these things on himself. This confusion can be compared to a lens that is out of focus... (Panayotis 2013: 12)

That could be understood as typical of our "New Dark Age" as James Bridle calls it (Bridle 2019), in which man no longer understands what is in the machine and therefore becomes unable to manage things. This could also mean that, on the romanticist scale of distinct to blurry, Big Data is often working poetically.

Secondly, if our screen-related inventions have more pixels than nature, could that mean that reality has descended on the scale - from the hyperrealities of mediated screen-centric lives towards vague poetry? The scale on which, once the only blurry thing was poetry with its power of abstraction, also belongs to reality now, where all the outlines are often not clear at all. So - compared to fiction, has nature along with our other everyday visuals moved to the poetic domain (Keevallik 2019)?

Blurriness - the fact of being neither transparent nor opaque, the ability to change form and evaporate - is an interesting feature that clouds have. We will look at this below in connection with concrete examples.

This concept justifies the choice of the weather as an apt subject - as poetical as possible - for the opera: the structure of the performance seems to resemble the logic of the weather; events just slide in as unexpectedly as clouds. At one point, it just starts raining cookies, as randomly as the "we value your privacy" icon pops up on our screens. (Figure 9) Everything that comes down from the clouds is of a hazardous

\section{nature. (Figure 10)}

The final accords are produced by Dido, in the role of Planet Earth, who has had enough and who literally makes the sky fall down - the clouds and "the Cloud People" (the choir in Magritte-sky-patterned costumes) descend to the ground. She uses a terrible roar to make this happen. The animal sound is here a parallel to the resonance that can destroy hard drives apparently there are precedents for sound breaking computers. For example, during a recent fire drill in a major Big Data centre in France, the cold extinguishing gas flowing from the pipes happened to create the same note as the heads of the hard drives, thus undermining their correct functioning.

At the same time, the Scientist who has climbed into a hot air balloon and left the Earth, is floating somewhere near the stratosphere and hearing "heavenly music". Proof of strange, beautiful sounds up in the clouds originates from the memories of the first people who went up with balloons. Even today, curious artists have dealt with the capture of cloud sounds ${ }^{3}$.

So, the final scene of the Cloud Opera shows a small hot air balloon floating above the huge clouds, under the numb looks of the silent cloud people, the only sound we hear is the Scientist's faraway voice jubilating: "Fantastic music! Unbelievable!!!"

This was a short overview of the Cloud Opera, touching upon some of the general aesthetical and dramaturgical questions. We will now take a closer look at how particular issues represented in the play and its specific details can be analysed with media archaeological means. (Figure 11)

\section{MEDIA THEORETICAL APPROACHES TO CLOUDS}

Let us look at the media archaeological approaches we could use to examine the clouds.

We choose not to use the so-called German branch of media archaeology here, which is focused mainly on the forms of technological mediation in media history. In connection to data clouds, we could discuss the technical development of computers, hard discs and data centres as such, but as for the metaphor of the "cloud" in computing, the history is quite short. And if we also want to include atmospheric

For instance, Nicholas Reeves, who created the CLOUD HARP that reads notes from the clouds with laser beams; or Usman Haque who sent mobile phones up to the sky to be able to "call the clouds" in the project he called the SKY EAR. 

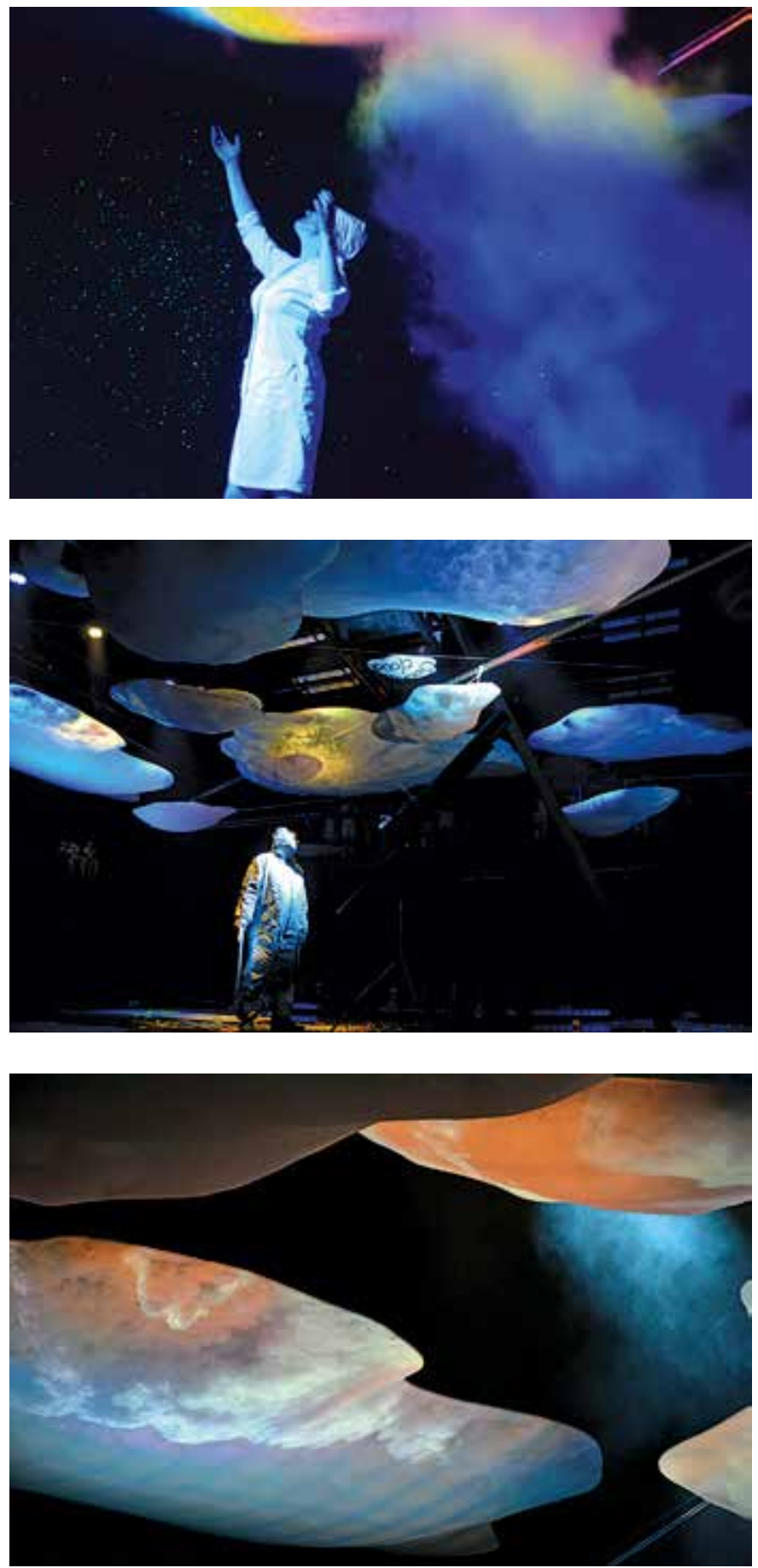

FIGURE 9. Different things randomly raining down from the clouds (photo: Liina Keevallik).

FIGURE 10. The Sound Cloud, playing music, driving by at a random moment (photo: Liina Keevallik).

FIGURE 11. The set for Cloud Opera (photo: Liina Keevallik). 
clouds, technology is much less relevant, unless we start drawing links between the techniques angels could use to support themselves on a cloud or how airplanes achieve this. Or comparing the microwaves of a giant internet server and a wind pushing a cloud across the sky. Or digging in the history of theatrical fog machines. In all of these cases, we would end up in the realm of poetry.

It makes more sense to look for analytic tools in the Anglo-American branch of media archaeology, for they are less focused on technological mediation, but are instead focused on changes in media technologies as cultural forms and on what patterns exist in how these changes come about.

John Durham Peters is not necessarily a media archaeologist, but a media theoretician, interested in the philosophical explorations of media's role in enabling the interactions of humans with the outside world. What is most interesting in this discourse, is his argument that clouds, along with the sea, fire and sky, are media - elemental media (Peters 2015). He starts out, however, by arguing that clouds present the very limit of the concept of 'media': "They (clouds) are the ultimate test of the idea that there could be natural media." He argues that as soon as one asks, "Do clouds have a meaning?" then any sailor, farmer or pilot would certainly say yes. Peters proposes that if they convey a meaning, it means they are mediating. Yet, he admits: "Clouds are par excellence, without inherent meaning (...) these floaty aerosols are saturated with water and with meaning that humans never put there. (...) Clouds resist ontology (Peters 2015)".

Shakespeare called them "airy nothings" ${ }^{\text {, }}$, the offended Scientist from the Cloud Opera says: "You are no sweet impressionist friends anymore, but aimless snowflakes of the new generation, lazy wobblers, unemotional windbags." That is, humans have been wonderers, always wondering whether clouds want to tell us something or not; whether it makes any sense to stare at them or not. Both Lucretius and Apollonius have insisted that there are no images in the clouds, they are not worth contemplating in order to find the shape of an animal. Peters, however, posits that if we ever want to learn the truth about the state of the world and the planet, then the clouds are the very place where to look for it. "This is some kind of crucial historical mutation: not only is it legitimate to look for images in the clouds, but it has become urgent. Our survival may depend on knowing how to read the signs in the atmosphere. (Peters 2015: 260)".

Peters' theory is interesting for exploring the real, the physical aspect of clouds their movement, the substance they are made of. For instance, blurriness - the fact of being neither transparent nor opaque, the ability to change form and evaporate - is the most interesting and the most frustrating feature that clouds have. It has always been a confusing thing: in painting, artists have never really found a solid ground for approaching these edgeless, surfaceless phantoms that defy the laws of perspective (Damisch 1972), while Leonardo recommended looking at blurry matter to find inspiration (de Vinci 2003). Peters' philosophy is exceptional because it deals with real atmospheric clouds (and inevitably with the things that people have projected on them), without falling for the fascinating metaphorical side. Strangely enough, the metaphorical viewpoint proves also to be a more practical approach: another media theoretician, Erkki Huhtamo, provides us with concrete analytic tools for media archaeological 'excavations'. He has called these units topoi. The concept was first coined by Ernst Robert Curtius (1973), a German literary scholar who was inspired by the classical rhetoric. His topoi were literary findings that served as cultural connectors and demonstrated the continuity of European literature across times and places. Huhtamo applies the concept of topoi to visual media culture: 
"The topos approach eschews the "new" which is so often the focus of media-cultural discourses, both critical and popular; instead, it emphasizes the clichéd, the commonplace and "the tired" (...) the new might be "dressed up" in formulas that may be hundreds of years old, while the old may provide "molds" for cultural innovations and reorientations" (Huhtamo, Parikka 2011: 14).

A topos thus functions as a reusable mould or vessel that, at different times, is filled with different substances. Huhtamo distinguishes three different roles that the topoi play:

a. Topoi as connectors to older cultural traditions. For instance, the "little people" often depicted in ads or in internet memes, pretending to live inside a computer, were also living in the gramophones in the beginning of the $20^{\text {th }}$ century. There were hundreds of publicity images showing brass bands and singers marching out of the gramophone's horn.

b. Topoi as commentaries and elaborations of media cultural forms, themes, practices and fantasies. Here, Huhtamo compares kaleidoscopes from the early $19^{\text {th }}$ century with today's mobile phones and assumes that both have forced men walk on the street with their gazes glued to the "machine" - a dangerous habit causing traffic accidents with either horse carriages or cars.

c. Topoi as vehicles of the culture of attractions and as motifs exploited by the culture industry.

Here we could think of various creatures breaking through the screens - like the ski jumpers that pierce the screen of a new
Samsung phone, for instance used to make the client believe that the product he is about to buy is really "revolutionary". The very same jumpers already sold us 'revolutionary' things a hundred years ago, the only difference is that instead of the screen, they jumped out of a painting or out of a photo. "The newest of the new is packaged in the oldest of the old (Huhtamo, Parikka 2011: 39)."

In the following, we will analyse the various modal representations of 'clouds' in the "Cloud Opera" through the lens of Peters' philosophy. We will also search for the various topoi in the play in terms of Huhtamo.

But before heading out for excavations, let us ask: what is the role of a topos in the process of artistic creation? It is not only a manifestation of a media cultural stereotype, its first "reason for existence" is to create poetic effects. How poetic effects emerge out of the creative use of rhetorical figures, from juxtaposing incommensurable textual elements, has been studied from Aristotle ${ }^{5}$ until Lotman (1976, see also Ibrus 2004) and others. But what if we want to understand how to use topoi creatively to construct and communicate new meanings - in ways that evoke various cultural universals or references in terms of Curtis, yet play with their constellations so that the outcome may be a critical reflection of the roots and uses of these topoi. To achieve this, we looked for practical approaches with similar goals within playful art forms (dramaturgical arts). We found Tarkovsky's theory (Tarkovsky 1981) of the use of clichés relevant for our purposes. He stated that a cinematic image is at its best when used in the most typical ways. His "cinematic image" (that can also be called a "cinematic figure") was his most important tool of creation; he considered it the climax of the 'Seventh Art'. He took note of the banal and simple visuals in his everyday 
surroundings and transferred them to the screen where they became "images" due to a new context. The more typical the raw material is, the more powerful an "image" it produces (Dobrovolski 2003). Such a game with topoi is different from the critical media theoretical game because of its practical purpose - amplifying the cliché with the help of a fresh context in order to create new meanings. It is important to mention that a good Tarkovskian image does not typically have a simple, straightforward meaning: it can usually be interpreted in alternative ways. Thus, the artistic use of topoi, while it builds on the theoretical knowledge and uses its concepts, is nevertheless a different approach due to its different aim. Yet, Huhtamo's topos can be fairly well actioned as a creator of figurative images on the screen as well as on the stage.

Therefore, as we analyse the "Cloud Opera" we can interpret these topoi to act as products of age-old cultural fermentation, but we should not ignore the fact that someone - one of us - has deliberately laid them there. That is, the combination of media archaeology and artistic research means being aware, firstly, of the cultural topoi in use in texts, secondly, of different historic contexts for these topoi in use, thirdly, of the artistic intention when using and possibly combining different topoi, and fourthly, of the eventual rhetorical effects of the combined use of the chosen topoi. In the following, we will look at where such creative and reflective use of topoi took us in terms of the eventual form of the play.

\section{MEDIA ARCHAEOLOGICAL FINDINGS}

One of the main inspirations for the Cloud Opera is the idea that the unknown still lives in the sky. Just like gods and angels and all the other invisible folks throughout the ages. We still project much that seems unclear to us (including the complex masses of vast datasets) onto the 'sky', from the personally controlled 'clouds' to the abstracted space of the world wide web. If, historically, the reason was clear - people really did not know what the clouds were hiding - then nowadays we perhaps know too much; we still seem to send the complicated and the shady up to the sky, metaphorically at least.

Of course, weather is always one of the unpredictable components of the sky. Peters takes Kittler's statement that "We can never separate the weather and the gods" and argues further: "The weather, with its intermittent reinforcement and irregular patterns of blessing and bane, behaves like gods and parents - one reason why we are so emotionally attached to it (Peters 2015: 244)". But is unpredictability really the reason we send the incomprehensible to the clouds?

Too much information is argued to bring ignorance. James Bridle states, we have not learned to think adequately for our age of technology. We are sitting on an enormous pile of information but we are unable to think of the big picture. He says it makes no sense to teach more people coding, it does not help them think bigger. Bridle brings an allegory of plumbing to describe our situation:
Learning to code is not enough, just as learning to plumb a sink is not enough to understand the complex interactions between water tables, political geography, ageing infrastructure, and social policy that define, shape and pro- duce actual life support systems in society. A simply functional understanding of systems is insufficient; one needs to be able to think about histories and con- sequences too. (Bridle 2019: 3)

He even suggests that instead of computational thinking, which is actually just solutionist thinking, it might be useful to adopt "cloudy thinking", which means giving up trying to understand it all. The data cloud system has been obscured anyhow, deliberately: "the cloud is a new kind of industry, and a hungry one. (Bridle 2019: 7)" Thus, humans tend to project their ignorance 
on the sky again and nourish the good old topos of the sky as a place for the unknown.

'Cloud' could be also understood as a fiasco metaphor for a safe place to store valuable information - it has a random shape, it has no boundaries, it can evaporate or rain down any minute... Just like in the Cloud Opera, where candy papers, cookies, and intimate information rained down just when one least expected it. The modern concern of losing all of one's work (in a cloud! In a cyber fog!) never occurred before, unless there was a major fire, a big flood or another natural catastrophe. Yet, it has become an everyday phenomenon that a silvery apparatus decides to show us our place and crash. Or the abstract forces that live natively in the clouds - like the computer viruses - may destroy our work, steal it, or block access to it.

The IT-genius who is rolling about on a couch-like cloud hanging from the ceiling like a swing (Figure 12), while his screen avatar is floating on a puff of real fog, refers to a widespread internet meme of businessmen lying on clouds with their laptops.

\section{(Figure 13)}

"Elevating the cult of magical new technology to where the Christian mythology situates heaven grants the businessman angelic powers denied from the crowd he has left behind on earth (Huhtamo 2015: 23)," says Huhtamo. We suggest that the contrasting double image of the IT-man and his avatar, is a depiction of this harsh reality. The idea of an airy, dreamy place without gravity for a weightless and free life is an illusion designed for sales; as in fact, most of the internet in terms of its materialities is hidden in the ground or in thick pipes at the bottom of the ocean and stored in huge warehouses in the suburbs.

If there is a topos to discover here, it could be the eternal conviction that the soft clouds are meant for the rulers of this world. No doubt that centuries ago the heavenly folks were seated on soft furniture, like that of the rich - which makes sense because they were at least as important as the kings. These days, such sofas have been passed on to businessmen. A contemporary Correggio-style ceiling fresco (Figure 14) could depict businessmen in suits rolling around with their laptops.

The next topos is contradictory to the first one. It speaks about the truth that still lives in the sky. The sky has been a place for truth since the dawn of the Western Civilization, for Plato and for many others. No wonder - the sky is a clock, a calendar, a weather indicator; it also shows us our place in the universe. A lot of these features only work with a clear sky. So, could clouds be responsible for the first topos, that of the unknown and ignorance?

Our data clouds, as blurry and dubious-looking as they are (unlike Apple's iCloud logo that has a nice and clear outline), still hold the truth. The data on people's medical or bank records, on almost every aspect of our social lives - collected and stored by the core knowledge-processing institutions of the 'information age'. Yet, there are also a lot of untruths in these clouds - the 'fake news', the 'deep fakes', the 'post-truths' and 'alternative facts'. These are mostly produced by new kinds of knowledge producers that, in any case, rely on a variety of topoi produced by some of the most oldest established institutions of truth projection. Namely, in most religions, the truth comes from the sky as well. And clouds tend to be useful in their narrative output, as it is so much easier to tell stories about a place that is out of focus. In the Cloud Opera, the nationalist Nurse/Virgin Mary suddenly descends from the skies and holds a fiery speech critiquing the computer cookies and praising their communion cookies that let Jesus alone spy in our souls. (Figure 15)

There is a high probability that she was the one to produce all the cookie crumbles and candy paper that rained down from the clouds before.

So, whatever the "truth", it still tends to descend from the heavens. Our ill-tempered Madonna descends with her truth on a Nuvola ${ }^{6}$ - a wooden cloud covered with cotton to blur the edges. 

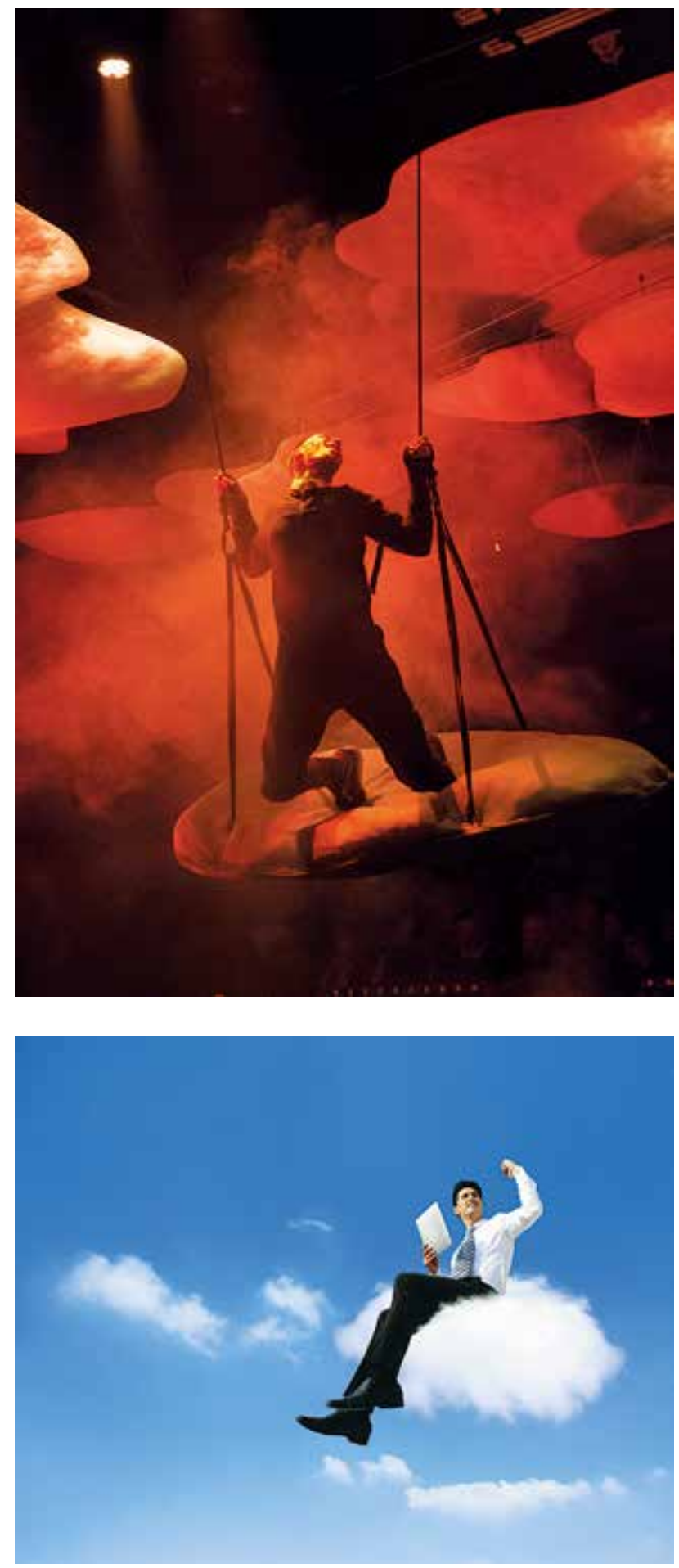

FIGURE 12. The It-genius on his cloud (photo: Markus Muide).

FIGURE 13. A typical internet meme of a businessman enjoying life on a cloud. 

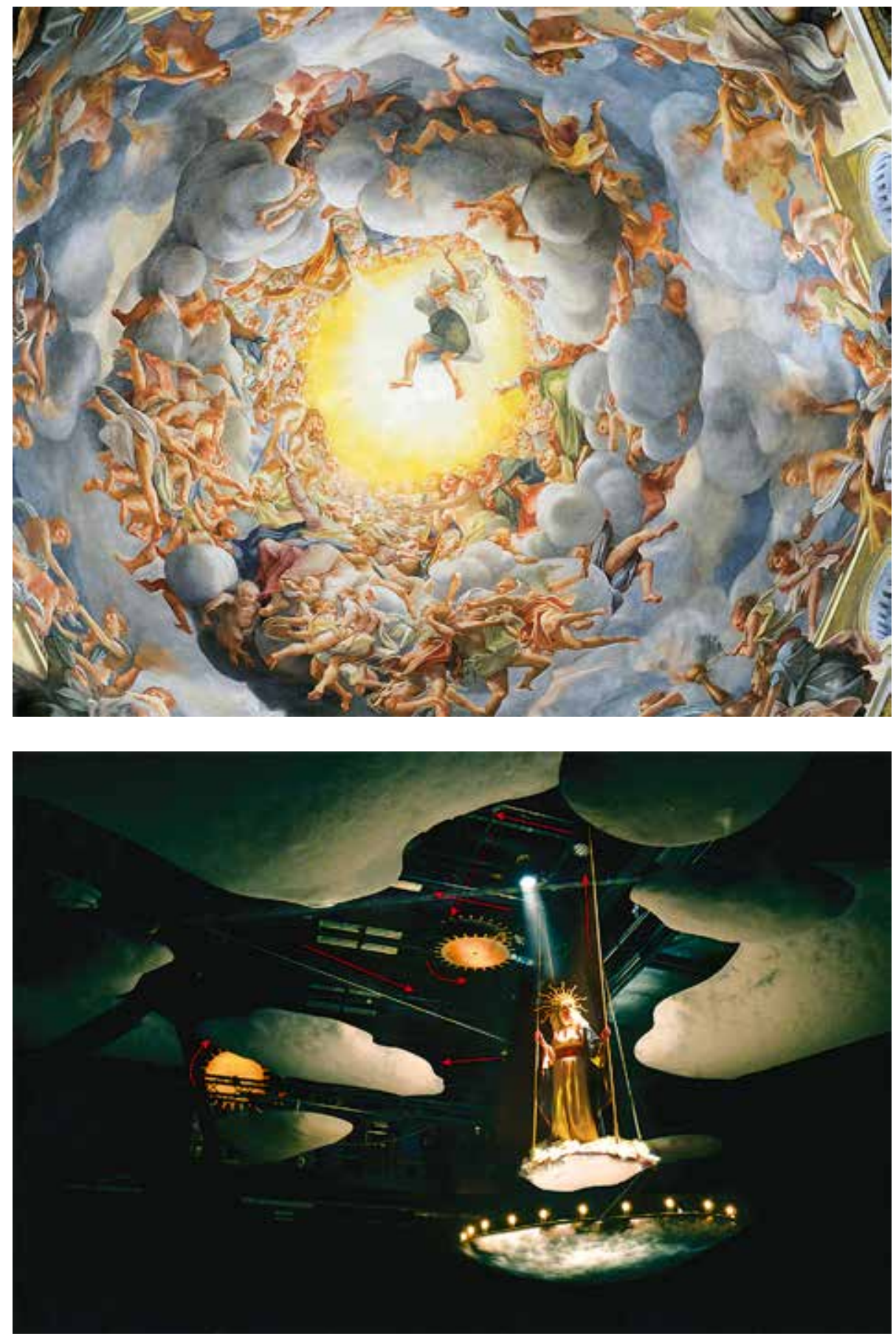

FIGURE 14. Antonio da Correggio The Assumption of the Virgin 1526-30.

Cathedral of Parma, Italy.

FIGURE 15. The nationalist Madonna holding a speech (photo: Markus Muide). 
The Renaissance "Nuvola" stands for a whole system of performances, usually played out in churches, using sophisticated systems of strings and pulleys to make characters fly around. These systems later developed into the famous Baroque theatre stage technology. (Figure 16)

The contemporary post-truth apparata use similar "elevators" to come down to us. The only thing that has changed is the technology - we no longer build our clouds of plywood and cotton, but can create invisible, metaphorical clouds. According to Huhtamo: "Conservative representations, including very old religious ones, are coated with layers of "newness" and awe. They may seem out of place in today's secular society, but are used to sell new technology, including things that on the surface are "from the future" (which can be a topos too). (Huhtamo 2015: 33)".

The invisibility of the new clouds is a problem. Because, like Huhtamo's "Little people", man needs someone to talk to inside the machine. In order to trust it, man wants to talk to the machine. Like the Scientist in the Cloud Opera who climbs the ladder with a huge padlock in his hands, to go and make sure he locks his poem up in a safe place. It is not easy for man to accept the invisible machine, and even if it is all hidden in a nice shiny box, it can make us nervous. That is one of the reasons for Bridle's statement that we have entered a new dark age. Even more - he declares that the real danger lies in us trying more and more to think like a computer and the computational thinking threatens to replace conscious thought. "The more obsessively we attempt to compute the world, the more unknowably complex it appears (Bridle 2019: 46)". Man can no longer ask the little people what they do inside the box, there is only Siri or some other chatbot constantly excusing itself of not being able to talk about everything yet. However, these simplistic voices are meant to compensate man's need to talk to the machine. Once they really can talk about everything, the danger of us speaking more and more like them becomes a reality.
Digging into clichés, we used quite a flagrant and well-established topos in the Cloud Opera. After the Scientist has decided to paint the clouds, a wicked cumulonimbus washes off the painting while it has been left alone for a moment. Although for the dramaturgy of the performance the fact that clouds have let the Scientist down again is more important, the rain doing harm is part of a universal topos: happiness needs Sun, sorrow needs rain, clouds bring danger. Especially when in the next scene, the Scientist, stricken with grief and sense of offence, addresses his monologue to the treacherous clouds.

The topos is working archetypically here. It is a cliché that it always rains when someone is sad in films. But also in books and in the everyday language, the dramatic clouds "gather above the head" of a hero in danger; the "sun comes out again" if new opportunities emerge; it is "raining in my heart" when love departs, etc. If Peters' sailor, farmer and pilot, known for their ability to communicate with the clouds, try hard to guess what the clouds are saying today, then the power of the metaphor exceeds all knowledge gained with years of experience - every child knows that rain is sad. All of our audio-visual production is so ultimately contaminated by the weather tropes used to amplify the drama (Forret, Keevallik 2019: 23-31) that we no longer notice it. We tend to notice the contrary: some artists have had the geniality of making the cliché run the other way around and, in these cases, the strange combination often produces new poetical effects. Agnès Varda is letting the flowers bloom and the sun shine on the background of the tragic drowning of a young and beautiful mother ${ }^{7}$; Tarkovsky makes the heavy rain fall down on a reunion of father and son ${ }^{8}$, simply because otherwise it would have been too melodramatic. But working the "right way", these tropes typically go unnoticed; they have melted into our visual surroundings, have become normalities. 


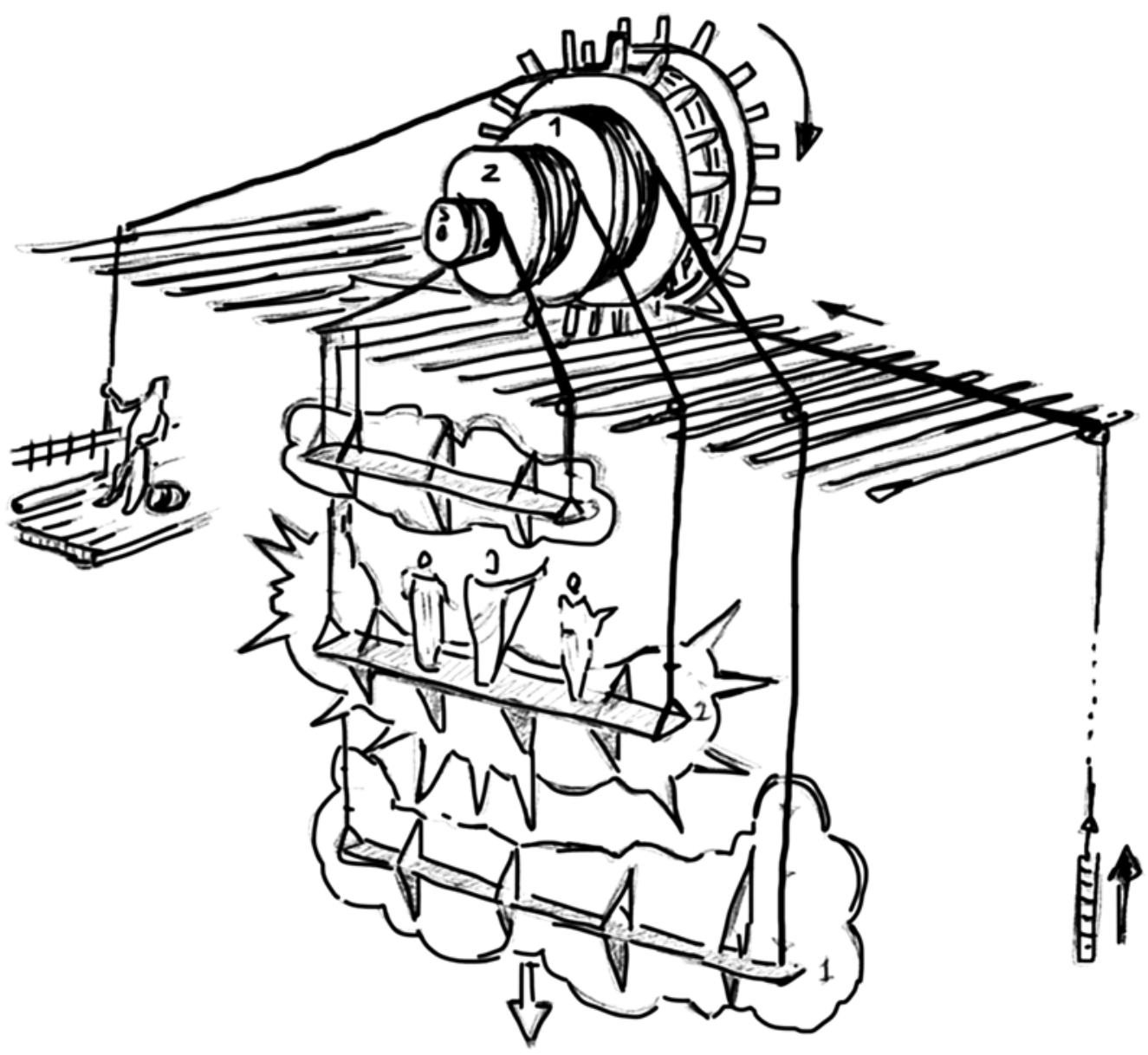

Jiis. 53 Caloire

FIGURE 16. One of the possible cloud systems of baroque theatre. Niccolo Sabbatini, Pratique pour fabriquer scènes et machines de théâtre, Ravenna, 1638, Library of the Warburg Institute, London. 
The last topos that we worked on in the Cloud Opera is actually a further development of the businessman-topos ("clouds are made for the rulers of the world") about IT-people acting like gods. Taking into account the previous topoi, they have the right to do so - their realm is in the clouds, they inhabit the former apartments of gods, with soft sofas, they and only know what is inside the machine, etc. In the Cloud Opera, the character IT-genius is wearing a motion capture suit so he can make his avatar move on the screen and do whatever he likes with it. (Figure 17) Motion capture as a technology has already been studied in connection with chronophotography and with Etienne-Jules Marey (Grosoli, Massuet 2014) who was already capturing the movements of people, birds and animals in the second half of the 19th century.

The IT-genius' major avatar is a beautiful buck who dances to seduce a victim in a dating app, but who becomes a cloud when his master loses his memory. (Figure 18) Is it not the worst that can happen to a digital character - losing its pixels?!

Once the IT-guy has created the 'cloud embassy' - he has managed to move all the data of a country into a tiny folder on the screen - we see the buck pushing the folder into a cloud with his back limb. (Figures

\section{$19,20)$}

The image is horrifying: it represents the young IT-guy acting irresponsibly, losing his grip and playing around with whole countries, as if it were all merely a football match. The second option for interpreting this is that the avatar represents a mysterious deer goddess of Ancient Siberia (Jacobson 1992) taking revenge on the technology as such. Related to this is the question of anonymity. The anonymity we can enjoy on websites is similar to that exploited by Zeus (or Jupiter) who used different 'avatars' when acting immorally. He appeared in the form of different birds and animals, and once even in the form of a cloud - when he wanted to make love to lo, he disguised himself in a cloud. (Figure 21)

And, of course, he was not the only god to pull that trick. Today, there is no need to be an 'IT guru', any man presenting himself under a false picture/identity on Tinder is playing God! In this broad context of the Western semiosphere in terms of Lotman (Lotman 1990) everybody on the internet can play God: first, s/he can "look down" on the whole planet, find what $\mathrm{s} /$ he wishes. Secondly, due to the anonymity, s/he can play all the roles he likes.

Regarding all the aforementioned examples, could we assume that Tarkovsky would be quite happy with the banality of the visual topoi in use? Could media archaeological methods be helpful in the creative process? At least, concerning Huhtamo's approach to the study of topoi, it seems to work as well as Tarkovsky's figure-picking trick: in the visual dramaturgy, the topoi look as typical as the poeticized everyday pictures of a genius filmmaker. Most of the creators probably act unconsciously while activating media archaeological instruments. This is also the case in the Cloud Opera. It has to be mentioned that the subject of the Cloud Opera is particularly "media archaeology-friendly" as its theme deals with rather basic and easily perceivable environmental elements, heavily used in artistic representations and discourses throughout history, it was quite easy to find images that work both as topoi and artistic figures.

But artists typically do not operate as systematically as media researchers - they would never tidy up their findings, they would scatter them around and hide them in probable and improbable places. To pick an example, let us look at the end of the opera: when Dido produces her final, scary sound and the whole cloud system descends slowly down to the stage, the chorus members, dressed in the "Magritte cloud" overalls, climb, one by one, down the ladder that unites the sky and the stage. (Figure 22)

As for the topoi, there are a couple of them functioning here - firstly "the sky as the place for the unknown"; secondly "there are little people working in the machine". As for the artistic figure, the image can tell us quite a few different stories: it either 

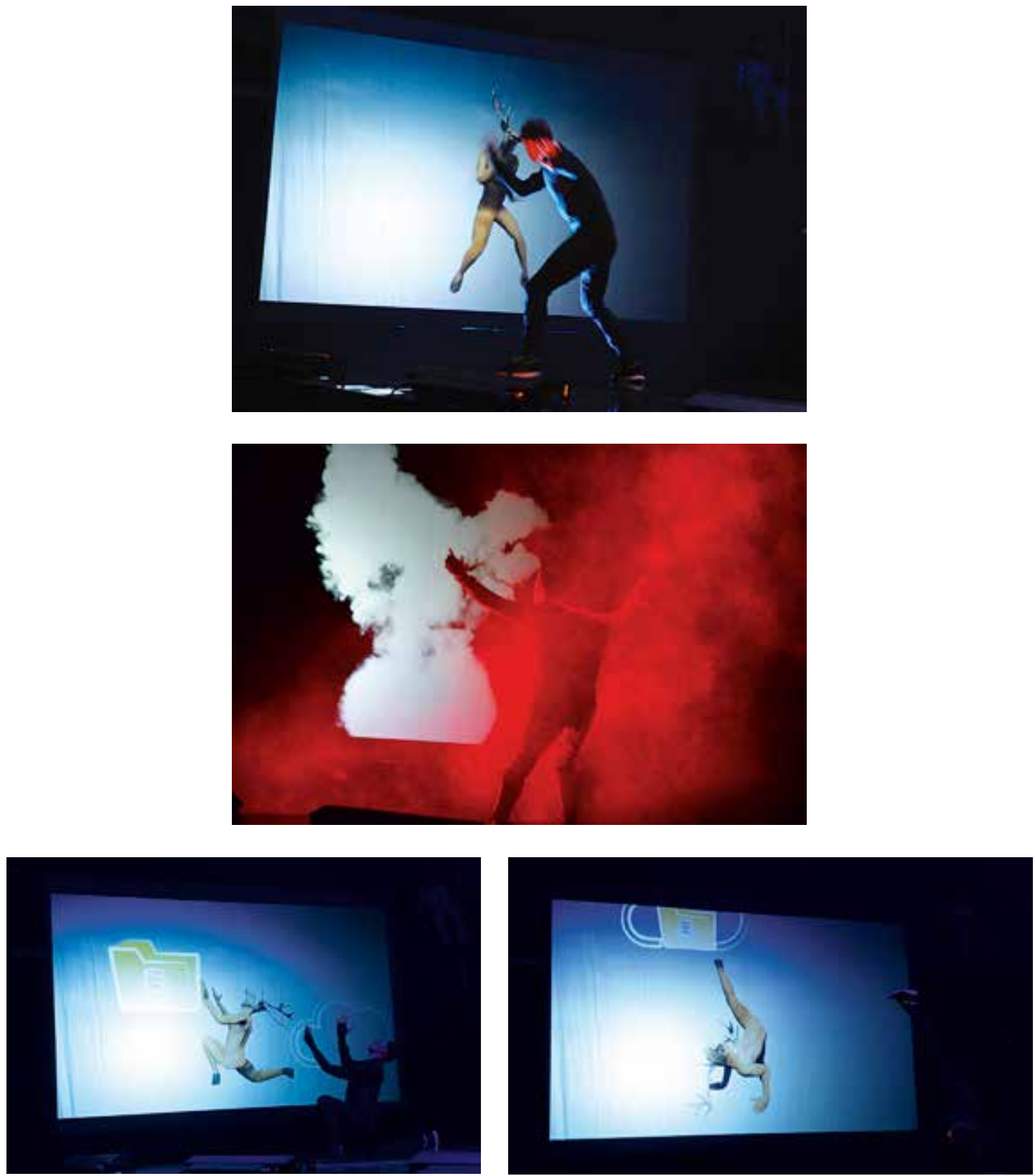

FIGURE 17. The IT-genius wearing the motion capture suit on stage (photo: Liina Keevallik).

FIGURE 18. The IT-genius' avatar turning into a cloud (photo: Liina Keevallik).

FIGURE 19. The IT-genius and his avatar moving a country to the cloud (with the help of the motion capture suit) (photo: Liina Keevallik).

FIGURE 20. The IT-genius and his avatar moving a country to the cloud (with the help of the motion capture suit) (photo: Liina Keevallik). 

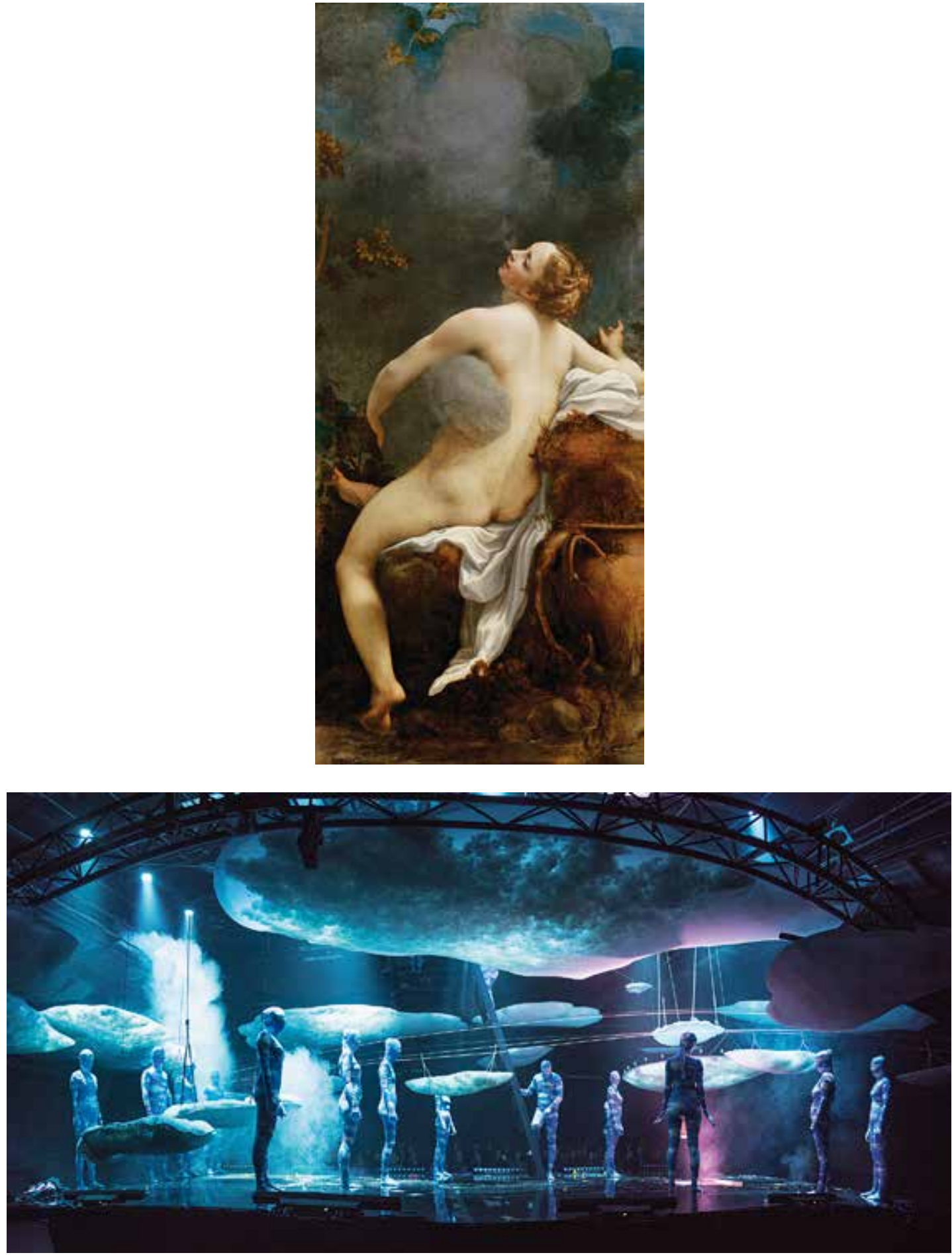

FIGURE 21. Antonio da Correggio Jupiter and Io, 1532-1533.

Kunsthistorisches Museum of Vienna, Austria.

FIGURE 22. The coming down of the Sky and the Cloud People (photo: Markus Muide). 
speaks about the terrifying visual emptiness, once we finally see the clouds from the mysterious "other side", there were nothing more than small clouds inside the big ones. Or: there is a new species of homo sapiens (or maybe Al?) working inside the cloud, weirdly numb and appearing to be nothing, just reflecting the surrounding landscape, now alone on this planet, observing the clouds from outside as if they had never seen them before... Or: the Magritte reference leading to the notion of surrealism as the only consolation left for impossible political situations, like it once was. Except the impossible situation might be natural this time? One cannot say that the image in question is purely "Tarkovskian", it is a little too theatrical for that, but it is more so than normal, because the genre we are dealing with is a little more than theatre - it is opera. What matters is the structure of the image and its shifted context - these have been worked out according to tarkovskian rules.

\section{CONCLUSION}

Clouds, real or metaphorical, can be wellobserved with media archaeological instruments. This article utilised Erkki Huhtamo's concept of topoi as its analytical toolset the topoi are the molds that reoccur at different times throughout history, every time filled with a new substance but still appearing to be similar, conditioning similar behaviour. As we have just seen, the topos study can also be applied to the creation of visual dramaturgy - there is a strong similarity between a visual topos and an image-cliché from everyday life that has the potential to become an artistic figure.

We observed different topoi that participated in the production of artistic figures, more or less tarkovskian, in the Cloud Opera. The performance merges, intertwines and mixes up atmospheric and data clouds. Why? It is not by chance that we have chosen media theoreticians like Peters and Huhtamo to help us study the matter. As one of them deals with real and the other with metaphorical clouds, it was exactly the two opposites that we needed.
Firstly, we would like to draw attention to the fact that data clouds are in fact as hazardous, as dangerous and as random as real clouds. Secondly, there are problems with both of the cloud types, like we mentioned in the beginning - both are getting closer and closer to a dangerous overdose on different substances. And the danger is real, in both cases, there is no metaphor there to save the day. So, the metaphor for "cloud computing" might be a scam for selling these invisible pillows with no clear boundaries, in which you can stuff as many things you have; but in fact, it appears to be a perfectly honest metaphor, referring to the actual drawbacks of our "personal clouds" that sound so nice and airy and light and secret!

An important conclusion for this research, both artistic and analytical, is the surprising self-evidence with which we still put away all confusing things into the sky. We still do it.

"Sky Media", like Peters calls all mediating subjects in the sky as seen from the earth, are particularly complex media. One of the reasons for this is definitely the following: "Compared to terrestrial media, celestial media - like aquatic media - are generally both more sublime and more abstract, in part because they can only rarely be touched by hand or by fire (...) The sky as a domain for human action up until recently has been almost entirely hands-free. (Peters 2015: 167)"

Things should be much simpler, now that we know "both sides", but we somehow still manage to complicate the issue once we understand, physically speaking, what is going on in the atmosphere, we create metaphors that blow things up again. Such as the smoke gun that the mad Scientist of the Cloud Opera points at the clouds - only to blur the blurred even more.

\section{(Figure 23)}




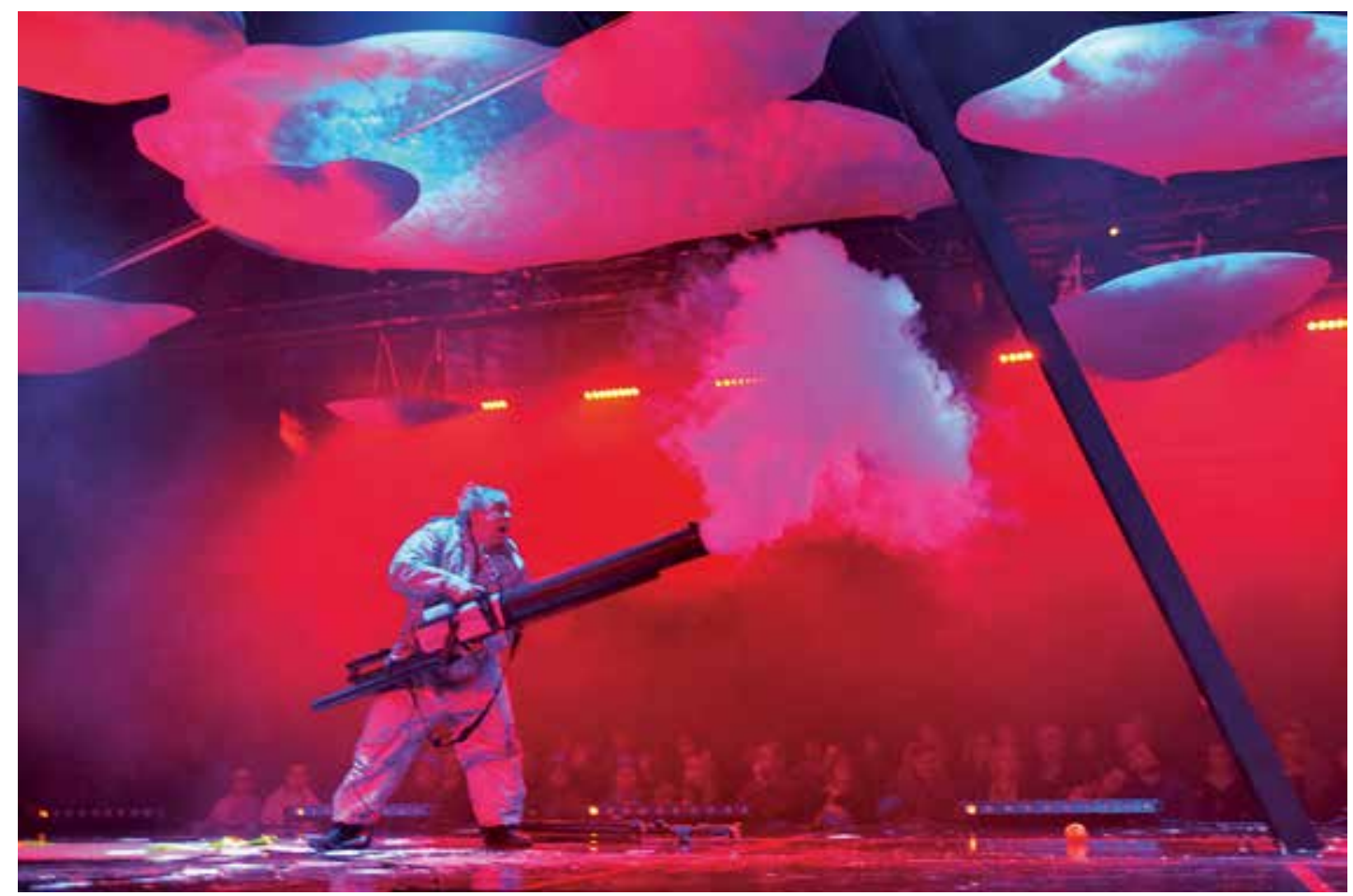

FIGURE 23. The Mad Scientist shooting at clouds (photo: Liina Keevallik). 
REFERENCES

Bridle, James (2019). New Dark Age. Technology and the End of the Future. London: Verso.

Curtius, Ernst Robert (1979 [1953]). European Literature and the Latin Middle Ages, trans. Willard

R. Trask. London and Henley: Routledge \& Kegan Paul. Damisch, Hubert (1972). Théorie du nuage. Pour une

histoire de la peinture. Paris: Editions du Seuil.

Dobrovolski, Andrei (2003). Master class, Tallinn,

Allfilm.

Eco, Umberto (1986). Travels in Hyperreality. San Diego: Harcourt.

Forret, Mélanie; Keevallik, Liina (2019). Poétique de la pluie du cinéma. In CinémAction 169 (La météo au cinéma: faire la pluie et le beau temps). Paris: Editions Corlet \& Télérama.

Grosoli, Marco; Massuet, Jean-Baptiste (dir.) (2014). La capture de mouvement ou le modelage de l'invisible. Presses Universitaires de Rennes.

Huhtamo, Erkki; Parikka, Jussi (2011). Media Archaeology. Approaches, Applications, and Implications. University of California Press Huhtamo, Erkki (2015). Obscured by the Cloud. Media archaeology, Topos Study, and the Internet. in: Thorsten Lomker (ed.), ISEA 2014 Dubai. Location. Proceedings of the $20^{\text {th }}$ International Symposium of Electronic Art, Dubai: Zayed University Books.

Ibrus, Indrek (2004). The Struggle for Grammar: Mechanisms of New Media Conventionalisation. In K. Kivimaa (Ed.), Opening Acts: New Media and Art in Estonia (pp. 23-37). Tallinn: E-media center, Estonian Art Academy.

Keevallik, Liina (2019). L'authenticité du flou. Sens public (Authentic Artifice), http://sens-public.org/ article1386.html?lang=en

Lotman, Yuri (1976). Analysis of the Poetic Text. Ann Arbor: University of Michigan Press.

Lotman, Yuri (1990). Universe of the mind: a semiotic theory of culture. Bloomington and Indianapolis: Indiana University Press.

Panayotis, Papadimitropoulos (2013). Le flou: visualité ou métaphore? La sémantique du flou. https://www.academia.edu/4331355/Le_flou_visualité_ou_métaphore_La_sémantique_du_flou Peters, John Durham (2015). The Marvelous Clouds: Toward a Philosophy of Elemental Media. Chicago; Londres: The University of Chicago Press.

Shakespeare, William (1595-96). The Midsummer Night's Dream

Tarkovsky, Andrei (1981). De la figure cinématographique. In Positif, 1981, 12, No 249. Lyon: Actes Sud. Uexküll, Jakob von (1957). A Stroll Through the Worlds of Animals and Men: A Picture Book of Invisible Worlds. In C. H. Schiller (Ed.), Instinctive Behavior: The Development of a Modern Concept (pp. 5-80). New York: International Universities Press.

Vinci, Léonard de (2003). Traité de la peinture. Paris:

Calmann Lévy. 